\section{BMJ Paediatrics Open}

\title{
Reactions of non-abused children aged 3-9 years to the Sexual Knowledge Picture Instrument: an interview- based study
}

Kirsten van Ham (D) , ${ }^{1}$ Sanne van Delft, ${ }^{2}$ Sonja N Brilleslijper-Kater, ${ }^{1}$ Rick R van Rijn, ${ }^{3}$ Johannes B van Goudoever, ${ }^{1}$ Johanna $\mathrm{H}$ van der Lee, ${ }^{4}$ Arianne $\mathrm{H} \mathrm{Teeuw}^{1}$

To cite: van Ham K, van Delft S, Brilleslijper-Kater SN, et al. Reactions of non-abused children aged $3-9$ years to the Sexual Knowledge Picture Instrument: an interview-based study. BMJ Paediatrics Open 2021;5:e001128. doi:10.1136/ bmjpo-2021-001128

- Additional supplemental material is published online only. To view, please visit the journal online (http://dx.doi.org/ 10.1136/bmjpo-2021-001128).

Received 14 April 2021 Accepted 8 July 2021

\section{Check for updates}

(c) Author(s) (or their employer(s)) 2021. Re-use permitted under CC BY-NC. No commercial re-use. See rights and permissions. Published by BMJ.

${ }^{1}$ Paediatrics, Amsterdam UMC Locatie AMC, Amsterdam, The Netherlands

${ }^{2}$ Paediatrics, Erasmus MC Sophia Children Hospital, Rotterdam, The Netherlands ${ }^{3}$ Paediatric Radiology, Amsterdam UMC Locatie AMC Amsterdam, The Netherlands ${ }^{4}$ Epidemiology, Kennisinstituut van Medisch Specialisten, Utrecht, The Netherlands

Correspondence to Dr Sonja N Brilleslijper-Kater; s.n.brilleslijper-kater@ amsterdamumc.nl

\section{ABSTRACT}

Background The Sexual Knowledge Picture Instrument (SKPI) is a child-friendly picture book that was developed as a diagnostic tool for sexual abuse in young children and is currently being validated. The aim of the current study was to explore the verbal and non-verbal reactions of nonabused Dutch children, aged 3-9 years, to the SKPI and to assess differences in reactions between genders and age groups.

Methods and analysis Subject recruitment took place at preschools and primary schools. All children underwent a recorded video semi-structured interview with the SKPI. Interview recordings were scored by an independent rater who used scoring lists for verbal and non-verbal reactions. Non-parametric tests were used in statistical analyses.

Results of the 90 children (median age 5 years) participating in the study, most correctly named the genitals and their non-sexual functions. Only 34 showed an understanding of the picture depicting adult sexuality, with just one child describing a sexual function. Girls $(n=45)$ gave more correct answers (median $87 \%)$ than boys $(n=45$, median $78 \% ; p=0.006)$. Giggling was the most frequently observed non-verbal reaction, with a total of 186 instances in 54 children.

Conclusion Non-abused children up to 9 years of age showed only limited knowledge of the sexual function of the genitals and hardly any insight into adult sexuality.

\section{INTRODUCTION}

The estimated worldwide prevalence of child sexual abuse (CSA) ranges between $0.4 \%$ and $31 \% .^{1-3}$ The consequences of CSA can be major, affecting both short-term and longterm health and having both physical (from acute injuries to life-long chronic diseases) and psychosocial (eg, depression, anxiety disorders, post-traumatic stress disorder (PTSD), substance abuse and difficulties in forming intimate and trusting relationships) manifestations. ${ }^{4-7}$ In order to offer timely and appropriate care for victims, it is necessary for medical and psychological care professionals to recognise CSA early.

\section{What is known about the subject?}

Regardless of the prevalence and devastating consequences of sexual abuse in young children, cases often go unrecognised by medical and psychological professionals.

- To date, no validated diagnostic instruments are available for evaluating cases of suspected sexual abuse in young children.

- Hardly any information is available on the sexual knowledge of non-abused children up to 9 years old.

\section{What this study adds?}

Non-abused children up to 9 years of age showed only limited knowledge of the sexual function of the genitals.

- Non-abused children up to 9 years of age showed hardly any insight into adult sexuality.

Related physical injuries might heal quickly, and young children in particular experience many barriers to disclosing abuse. ${ }^{8-10}$ Symptoms of PTSD and age-inappropriate sexual behaviour and knowledge are considered the most commonly identified signs of CSA. ${ }^{11}$

Meanwhile, research on adult survivors of CSA shows that some of the cues the survivors gave as young children, such as telling about the abuse 'in their own words' or showing non-verbal and behavioural signs, remained unidentified by professional caregivers over time. ${ }^{912-14}$

The Sexual Knowledge Picture Instrument (SKPI) is a child-friendly picture book that was developed for professionals to assess a child's knowledge of intimate body parts, intimacy, and adult sexuality, and to observe their non-verbal reactions at the same time. ${ }^{11}$ The pictures show daily routines in the lives of most children, gender differences, body 
parts and their functions, and normal intimate behaviour between children and/or adults. A manual for professionals was also developed. The manual contains instructions, a semi-structured interviewing protocol, and a scoring list for the evaluation of verbal and non-verbal reactions of the child. The SKPI is currently being validated in a study to determine its value as a diagnostic tool for CSA in young children. ${ }^{15}$ The main hypothesis in this study is that abused children can be distinguished from non-abused children by their verbal and non-verbal reactions to the instrument, and that looking at the pictures may lower the burden for abused children to disclose. ${ }^{15}$

As a first step in the validation of the SKPI, the current study investigated the verbal and non-verbal reactions to the SKPI in a group of non-abused Dutch children between the ages of 3 and 9 . The aim of this study was to establish 'normal' values of verbal and non-verbal responses to the SKPI. We expected to see no non-verbal responses related to stress or discomfort during the interviews. An additional aim of the current project was to compare the sexual knowledge of boys and girls. The hypothesis was that we would find no differences in the sexual knowledge of young, non-abused boys and girls.

In our validation study currently being conducted, the reactions of the non-abused children will be compared with the verbal and non-verbal reactions of a group of (alleged) victims of CSA and the and inter-rater and intrarater reliability of the SKPI are investigated.

\section{METHODS}

\section{Study population}

Children between the ages of 3 and 9 years were included in the study. Recruitment took place by approaching parents from multiple schools and preschools across the country. Current or earlier sexual abuse in children was ruled out as much as possible by administering parental questionnaires that included questions about any history of (suspected) abuse. Other child-based exclusion criteria were a visual or cognitive impairment, a previous interview with the SKPI or a diagnosis of a psychiatric/ behavioural disorder.

\section{Study procedures}

For a detailed description of the procedure for child interviews with the SKPI, we refer to the published protocol of the validation study. ${ }^{15}$

The first two pictures of the SKPI show ordinary home situations for most Dutch children. With the accompanying questions, these images allow the child to become more comfortable. The rater is able to observe and score the child's 'baseline' non-verbal behaviour.

The following 13 pictures and questions assess the child's verbal sexual knowledge and non-verbal reactions across five topics: gender differences (pictures 3, $4,6)$, male and female genitals and buttocks and their functions (pictures $4,5,7,8$ ), adult intimacy (pictures
$9,10)$ and child/child or child/adult intimacy (pictures 11-15).

Each verbal reaction in response to the questions is scored as 'correct', 'incorrect', 'refusal to answer' or 'other ...' '. Some of the correct answers are further separated into different options (eg, with or without mentioning the genitals, or adding a sexual function of the genitals). To determine a verbal score for each individual child, correct and incorrect answers were scored as 1 and 0 , respectively. Total scores were calculated for each of the five topics. For the non-verbal test score, the rater could check for 24 different non-verbal reactions in the child as they responded to each picture.

In the current study, the recorded video child interviews were scored by an independent rater (SvD). Coded data were collected in Castor EDC, a General Data Protection Regulation (GDPR) compliant encrypted digital database. ${ }^{16}$

\section{Patient and public involvement}

During the design of the study, parents/caregivers from (potential) subjects assisted us in creating a recruitment strategy and helped to ensure that the methods selected were appropriate. We intended to share the final results of the study with all parents/caregivers and will continue involving them in the development of an appropriate method of dissemination of the study results.

\section{Statistical analysis}

All data were analysed using SPSS (V.25.0, IBM). Categorical variables were reported as numbers and percentages. The Mann-Whitney $\mathrm{U}$ test was used to compare the scoring results between boys and girls. $\mathrm{P}$ values $<0.05$ were considered statistically significant.

\section{RESULTS}

A total of 171 preschools and primary schools were approached and informed about the study. Thirty-one schools $(18 \%)$ gave permission to inform the parents of the students, and 89 children were recruited to participate in the study. Seven children, recruited from the personal networks of the researchers, were added. Of these 96 children, 6 children were excluded based on the exclusion criteria $(n=3)$ or technical problems during the interview $(n=3)$.

\section{Baseline characteristics}

The total study group consisted of 90 children. Ages were evenly distributed, with a median (IQR) age of $5(4-7)$ years. The group consisted of 45 boys and 45 girls. Eightynine children, 85 mothers and 86 fathers were born in the Netherlands. Ten children spoke a second language (ie, Amharic (Ethiopia), English, German, Indonesian, Spanish and Swedish). During the first 22 interviews, a preliminary version of the manual, which did not contain questions 8 and 10 , was used. Sometimes a question could not be asked, for example, if the child persistently wanted 
Table 1 Median (IQR) number of correct answers per topic for the total study group and for each gender and age group

\begin{tabular}{|c|c|c|c|c|c|}
\hline $\begin{array}{l}\text { Topic: } \\
\text { possible range }\end{array}$ & $\begin{array}{l}\text { Gender } \\
\text { differences } \\
0-6\end{array}$ & $\begin{array}{l}\text { Genitals and } \\
\text { functions } \\
0-10\end{array}$ & $\begin{array}{l}\text { Adult intimacy } \\
0-2\end{array}$ & $\begin{array}{l}\text { Child-adult } \\
\text { intimacy } \\
0-5\end{array}$ & $\begin{array}{l}\text { Total } \\
0-23\end{array}$ \\
\hline Total $(n=90)$ & $5(4-6)$ & $8(6-10)$ & $1(1-2)$ & $4(3-5)$ & $19(17-21)$ \\
\hline Girls $(n=45)$ & $6(5-6)$ & $9(7-10)$ & $2(1-2)$ & $4(4-5)$ & $20(18-21)$ \\
\hline Boys $(n=45)$ & $5(4-6)$ & $7(5.5-10)$ & $1(1-2)$ & $4(3-5)$ & $18(14-20)$ \\
\hline $\begin{array}{l}\text { P value (Mann-Whitney } \\
\text { test) }\end{array}$ & 0.012 & 0.056 & 0.060 & 0.071 & 0.006 \\
\hline 3 years $(n=9)$ & $3.5(3-4.25)$ & $4.5(2-9)$ & $1(1-1.25)$ & $2(1-3))$ & $12.5(7.5-16.25)$ \\
\hline 4 years $(n=19)$ & $5(4-6)$ & $8(6-9)$ & $1(1-2)$ & $4(3-4)$ & $19(15-20)$ \\
\hline 5 years $(n=22)$ & $6(5.75-6)$ & $8.5(6-10)$ & $1(1-2)$ & $4(3.75-5)$ & $20(17.75-21.25)$ \\
\hline 6 years $(n=15)$ & $5(4-6)$ & $8(7-9)$ & $2(1-2)$ & $4(3-5)$ & $18(17-21)$ \\
\hline 7 years $(n=12)$ & $6(5-6)$ & $10(8.25-10)$ & $1(1-2)$ & $4(4-5)$ & $21(19.25-22)$ \\
\hline 8 years $(n=12)$ & $4.5(4-6)$ & $9.5(7-10)$ & $1(1-2)$ & $5(4-5)$ & $19.5(18-21)$ \\
\hline
\end{tabular}

to continue to the next picture (this particular reaction was scored as a non-verbal reaction).

\section{Verbal scoring}

Table 1 shows the median (IQR) total score and median (IQR) score for each topic for the total sample and divided by gender or age in years. The Mann-Whitney test was used to compare the medians from boys and girls.

Girls had more correct answers than boys in all topics, as is illustrated in table 1 .

Table 2 shows the number of children in the total study population, and boys and girls separately, who gave a correct answer to each of the individual questions. Questions answered correctly more than $95 \%$ of the time and less than $75 \%$ of the time in the total sample are marked green and orange, respectively.

Eighty-nine children were able to identify the dressed boy and girl, and 81 knew their own gender. Forty-one children correctly explained how the boy and girl were different, and four children named genital differences. While most children showed adequate knowledge of the urinating function of the female and male genitals, only one 6-year-old girl added sexual functions. The correct function of the female breasts (breastfeeding) was given by 53 children.

Eighty-eight children showed insight into the situation of the kissing adults and described the characters on the picture as 'being in love', 'getting married', 'hugging' or 'kissing'. Thirty-four children gave a correct 'sexual' connotation to the situation in picture 10. Five children refused to answer and 51 showed no, or very basic, insight (eg, a description, such as, 'Mummy and daddy are lying down, looking at each other').

The complete verbal scoring result table, a ranking of the scorings per question and the elaborated verbal reaction tables from the total sample, for boys and girls and for different age groups are available as online supplemental appendices $1-3$, respectively.

\section{Non-verbal scoring}

Table 3 displays the most frequently observed non-verbal reactions (at least 20 times in total), for each picture. A complete table that displays the observed frequency of all 24 non-verbal reactions that could be scored for each picture is available as an online supplemental appendix 4.

Picture 4 (naked boy and girl) elicited the highest number of reactions $(n=56$, in 40 children), followed by picture 7 (naked man and woman) (n=53, in 35 children).

Giggling was the most frequent non-verbal reaction. Giggling was observed 186 times in 54 children, usually as a reaction to pictures 4 and 5 (front and back of naked boy and girl), pictures 6 and 7 (naked man and woman), picture 10 (man and woman making love) and picture 11 (children's play). This was followed by excessive movements (eg, wiggling legs/feet or fidgeting with fingers), which was recorded 80 times in 26 children as 'unable to sit quietly'. It is important to notice that, just as trying to turn to the next page, this reaction was mostly seen in children who demonstrated the same behaviour when shown the first two (baseline) pictures, which lacked any sexual connotations.

Five children walked away during the interviews. Two children (ages 3 and 4) walked away after looking at the baseline pictures, one child (age 4) when seeing picture 7 (naked man and woman) and one child (age 4) when seeing picture 10 (man and woman making love). Five possible non-verbal reactions were never observed: 'crying', 'looking angry', 'sitting in a hunched way', 'hiding face (in clothes/hair)' and 'not able to score because child refuses to participate'.

The complete, elaborated non-verbal reaction table, showing the non-verbal reactions of each individual child to each picture is available on request from the authors. 


\section{DISCUSSION}

We aimed to reveal the verbal and non-verbal reactions of non-abused Dutch children 3-9 years of age to the SKPI to gain insights into their sexual knowledge. The second aim was to compare the sexual knowledge of boys and girls and children of different ages. The results of this study will also be used in a validation study comparing the reactions of the non-abused participants in this study with the verbal and non-verbal reactions of a group of (alleged) victims of CSA.

With a median of 19 correct answers out of 23, we showed that most non-abused young Dutch children had knowledge of gender differences, genitals and their functions and intimacy. When comparing the different topics present in the SKPI, children had more limited knowledge of the sexual function of the female (child and adult) genitals than of the male genitals. On the topic of adult intimacy, while picture 9 (kissing man and woman) was often interpreted correctly, picture 10 (man and woman making love) was mostly described without any sexual connotation. Children showed more insight into the intimate situations between children and between adults and children (picture 11-15). Of these pictures, picture 12 (doctor examining a child) and 15 (crying child in bed) were the most challenging to participants. These two pictures may have been too difficult for the children to interpret properly. For example, some children justifiably interpreted picture 12 as a father changing the diaper of a toddler, which was considered correct in this study.

\begin{tabular}{|c|c|c|c|c|}
\hline Topic & Question & $\begin{array}{l}\text { Total } \\
(\mathrm{n}=90)\end{array}$ & $\begin{array}{l}\text { Boys } \\
(n=45)\end{array}$ & $\begin{array}{l}\text { Girls } \\
(n=45) \\
n^{/ N}\end{array}$ \\
\hline \multirow[t]{6}{*}{ Gender differences } & 1. Identification dressed boy/girl & $89^{/ 89}$ & $44^{/ 44}$ & $45^{/ 45}$ \\
\hline & 2. Explanation gender dressed boy/girl & $76^{183}$ & $34^{/ 40}$ & $42^{/ 43}$ \\
\hline & 4. Explanation own gender & $41^{/ 81}$ & $15^{/ 40}$ & $26^{/ 41}$ \\
\hline & Incl. genital differences & 4 & & 4 \\
\hline & 5. Identification naked boy/girl & $89^{/ 89}$ & $44^{/ 44}$ & $45^{/ 45}$ \\
\hline & 6. Explanation gender difference naked boy/girl & $79^{/ 88}$ & $36^{/ 44}$ & $43^{/ 44}$ \\
\hline \multirow{4}{*}{$\begin{array}{l}\text { Children's genitals and their } \\
\text { functions }\end{array}$} & Incl. sexual function & 1 & & 1 \\
\hline & 9. Naming of boy's genitals & $79^{/ 81}$ & $39^{/ 40}$ & $40^{/ 41}$ \\
\hline & 10. Function of boy's genitals* & $62^{/ 64}$ & $31^{/ 32}$ & $31^{/ 32}$ \\
\hline & Incl. sexual function & 1 & & 1 \\
\hline \multirow{5}{*}{$\begin{array}{l}\text { Adult's genitals and their } \\
\text { functions }\end{array}$} & 11. Naming of breasts & $79^{/ 89}$ & $36^{/ 44}$ & $43^{/ 45}$ \\
\hline & 12. Function of breasts & $53^{/ 88}$ & $21^{/ 44}$ & $32^{144}$ \\
\hline & 13. Naming of female genitals & $66^{190}$ & $28^{/ 45}$ & $38^{/ 45}$ \\
\hline & 14. Function of female genitals & $79^{/ 85}$ & $37^{142}$ & $41^{/ 43}$ \\
\hline & Incl. sexual function & 1 & & 1 \\
\hline \multirow{4}{*}{ Child intimacy } & 20. Insight doctor examining child & $48^{190}$ & $26^{/ 45}$ & $22^{/ 45}$ \\
\hline & 21. Insight male bent over girl in bed & $74^{190}$ & $37^{/ 45}$ & $37^{/ 45}$ \\
\hline & 22. Insight female washing boy in shower & $84^{190}$ & $40^{/ 45}$ & $44^{/ 45}$ \\
\hline & 23. Insight crying child in bed with female & $62^{190}$ & $25^{/ 45}$ & $37^{145}$ \\
\hline
\end{tabular}

${ }^{*}$ Question missing in primary version of the manual. 
Table 3 Number of children from the total sample $(n=90)$ that showed a non-verbal reaction to each picture

\begin{tabular}{|c|c|c|c|c|c|c|c|c|c|c|c|c|c|c|c|}
\hline $\begin{array}{l}\text { Picture } \\
\text { reaction }\end{array}$ & 1 & 2 & 3 & 4 & 5 & 6 & 7 & 8 & 9 & 10 & 11 & 12 & 13 & 14 & 15 \\
\hline Silent/saying little & 5 & 2 & 1 & 3 & 3 & 1 & 2 & 2 & 4 & 1 & 3 & 2 & 2 & 1 & 1 \\
\hline Speaking softly & 6 & 2 & 1 & 4 & 1 & 1 & 2 & 1 & 1 & 1 & 1 & 1 & 2 & 1 & 1 \\
\hline Other voice & 1 & 1 & 1 & 3 & 3 & 3 & 6 & 1 & - & 2 & 3 & 3 & 2 & 3 & - \\
\hline Giggling & 5 & 8 & 5 & 29 & 24 & 9 & 21 & 16 & 14 & 16 & 19 & 3 & 6 & 6 & 5 \\
\hline To next picture & 7 & 9 & 3 & 3 & 1 & 4 & 4 & 2 & 5 & 4 & 5 & 5 & 3 & 6 & 7 \\
\hline Avoiding eye contact & 1 & 1 & 2 & 2 & 2 & 2 & 2 & 1 & 1 & 1 & 1 & 1 & 2 & 1 & 2 \\
\hline Distracting & 1 & 5 & 3 & 1 & 1 & 5 & 2 & 1 & 4 & 1 & 3 & 2 & 3 & 2 & 4 \\
\hline Not able to sit quietly & 6 & 6 & 1 & 5 & 3 & 8 & 6 & 5 & 7 & 6 & 6 & 2 & 5 & 6 & 8 \\
\hline
\end{tabular}

Reactions to the baseline pictures are marked in grey.

Although we expected to find similar knowledge in girls and boys, we did find some differences. However, the median age of girls in our sample was higher (6 years vs 5 years), and only two girls were 3 years old, compared with six of the boys.

Using a similar picture instrument as the SKPI in a study 20 years ago, Brilleslijper-Kater et al did not find differences in sexual knowledge between boys and girls. ${ }^{17}$ It is important to recognise the different age range (2-6 years) in the previous study and the relatively small sample sizes of both studies.

With a median of 12.5 correct answers out of 23 , the number of correct answers was clearly the lowest in the 3-year-old group. However, the median number of correct answers was similar for the older age groups. The limited sizes of the different age groups did not allow us to investigate further the age-related differences in sexual knowledge.

Overall, the children seemed relaxed during the interviews, and did not show non-verbal reactions that could be clearly related to stress or discomfort.

Giggling was by far the most common non-verbal reaction. Although giggling at the introduction pictures was observed in 12 children, this was also the most frequent reaction to the pictures that showed nudity.

\section{Strengths and limitations of this study}

Before using and scoring the SKPI, all interviewers and the rater were trained by a child psychologist, enabling them to conduct the interview and to use the scoring forms in a uniform and reliable way. Still, the use of the SKPI may have limitations. For example, it relies on whether or not the child is following the given instructions and willing to demonstrate (all) his/her knowledge.

The recruitment of children in the study was difficult; the majority of schools we approached indicated that the sensitivity of the topic was their main reason not to facilitate our study. Even if the schools were willing to facilitate recruitment, few parents were interested in participating with their child. As a result, the sample size of our study $(n=90)$ was smaller than the intended study size $(n=100)$. The small sample size also prevented a more detailed comparison of the sexual knowledge between children of different ages.

Except for the previous study by Brilleslijper-Kater $e t$ al using a similar instrument, we did not find any information in the literature regarding other studies, or other methods to explore sexual knowledge in young, nonabused children.

Furthermore, the generalisability of our findings to the general population in the Netherlands is limited. Despite our attempts to reach parents and children with different ethnic and cultural backgrounds, we were not able to include many children with non-Dutch backgrounds, even though they form an important part of the Dutch population.

Current or earlier sexual abuse of the children was ruled out using the parental questionnaire. However, it is impossible to completely rule out CSA. If the responses to the questionnaires did not give any warning signs, we assumed the child did not experience CSA.

\section{Implications for the validation study}

In the next step for the determination of the diagnostic accuracy and the value of the SKPI, the scorings from the current sample of non-abused children will be compared with the scorings from a sample of suspected victims of sexual abuse. The scorings will be evaluated by a blinded, independent rater. We will determine if any differences are present between the groups, suggesting that suspected victims have more or less knowledge of adult sexuality, by comparing total verbal scoring results. It may also be relevant which, and how many, non-verbal reactions are shown by suspected victims and if reactions absent from the current study are noted in the case group.

\section{CONCLUSION}

Non-abused Dutch children, aged 3-9 years, who were interviewed with the SKPI demonstrated knowledge of gender differences and children's genitals. They showed only limited knowledge of the sexual function of the genitals or insight into adult sexuality. The girls in this study, 
who were slightly older on average than the boys, gave more correct answers than the boys on most questions.

Giggling was the most common non-verbal reaction and was mostly observed in response to the pictures that showed nudity.

Acknowledgements We would like to express our sincere gratitude to all the children who participated in the study, as well as their parent(s)/caregiver(s).

Contributors AHT, KvH, SB-K, RvR, JBvG, and HvdL conceived of the study and initiated the study design. $\mathrm{KvH}$ and SvD performed data collection, data analysis and interpretation, and KvH drafted the article. HvdL provided statistical expertise in clinical trial design and conducted the primary statistical analysis. All authors contributed to refinement of the study protocol and critical revision of the article, and all of them approved the final manuscript.

Funding This work was supported by the Contribute Foundation, the Healthcare Insurers Innovation Foundation $(2.969 ; 2016 / 020201)$ and the Janivo Foundation (2015.444)

Competing interests None declared.

Patient consent for publication Not required.

Ethics approval This study has been approved by the Medical Research and Ethics Committee (MREC) from the Amsterdam UMC Hospital (Academic Medical Centre location, AMC), under approval number 2015_173.

Provenance and peer review Not commissioned; externally peer reviewed.

Data availability statement Data may be obtained from a third party and are not publicly available. All data relevant to the study are included in the article or uploaded as supplementary information. Data may be obtained from a third party and are not publicly available. All study data will be stored according to Good Clinical Practice guidelines. Coded data from the subject scoring and questionnaires will be stored in the online study database from Castor Castor Electronic Data Capture. For privacy reasons, the video recordings will be stored in a separate, locked database on the Amsterdam UMC data server in which it can only be approached by the coordinating researcher and one of the local coinvestigators. The recordings will be erased 1 year after the study's final analysis.

Supplemental material This content has been supplied by the author(s). It has not been vetted by BMJ Publishing Group Limited (BMJ) and may not have been peer-reviewed. Any opinions or recommendations discussed are solely those of the author(s) and are not endorsed by BMJ. BMJ disclaims all liability and responsibility arising from any reliance placed on the content. Where the content includes any translated material, BMJ does not warrant the accuracy and reliability of the translations (including but not limited to local regulations, clinical guidelines, terminology, drug names and drug dosages), and is not responsible for any error and/or omissions arising from translation and adaptation or otherwise.

Open access This is an open access article distributed in accordance with the Creative Commons Attribution Non Commercial (CC BY-NC 4.0) license, which permits others to distribute, remix, adapt, build upon this work non-commercially, and license their derivative works on different terms, provided the original work is properly cited, appropriate credit is given, any changes made indicated, and the use is non-commercial. See: http://creativecommons.org/licenses/by-nc/4.0/.

ORCID iD

Kirsten van Ham http://orcid.org/0000-0001-6328-7123

\section{REFERENCES}

1 Barth J, Bermetz L, Heim E, et al. The current prevalence of child sexual abuse worldwide: a systematic review and meta-analysis. Int J Public Health 2013;58:469-83.

2 Pereda N, Guilera G, Forns M, et al. The prevalence of child sexual abuse in community and student samples: a meta-analysis. Clin Psychol Rev 2009;29:328-38.

3 Stoltenborgh M, van ljzendoorn MH, Euser EM, et al. A global perspective on child sexual abuse: meta-analysis of prevalence around the world. Child Maltreat 2011;16:79-101.

4 Chen LP, Murad MH, Paras ML, et al. Sexual abuse and lifetime diagnosis of psychiatric disorders: systematic review and metaanalysis. Mayo Clin Proc 2010;85:618-29.

5 Maniglio R. The impact of child sexual abuse on health: a systematic review of reviews. Clin Psychol Rev 2009;29:647-57.

6 Pereda N, Guilera G, Forns M, et al. The International epidemiology of child sexual abuse: a continuation of Finkelhor (1994). Child Abuse Negl 2009;33:331-42.

7 Wegman HL, Stetler C. A meta-analytic review of the effects of childhood abuse on medical outcomes in adulthood. Psychosom Med 2009;71:805-12.

8 Adams JA. Medical evaluation of suspected child sexual abuse: 2011 update. J Child Sex Abus 2011;20:588-605.

9 Alaggia R, Collin-Vézina D, Lateef R. Facilitators and barriers to child sexual abuse (CsA) disclosures: a research update (2000-2016). Trauma Violence Abuse 2019;20:260-83.

10 McElvaney R, Greene S, Hogan D. To tell or not to tell? factors influencing young people's informal disclosures of child sexual abuse. J Interpers Violence 2014;29:928-47.

11 Brilleslijper-Kater SN, Friedrich WN, Corwin DL. Sexual knowledge and emotional reaction as indicators of sexual abuse in young children: theory and research challenges. Child Abuse Negl 2004;28:1007-17.

12 Brattfjell ML, Flåm AM. "They were the ones that saw me and listened." From child sexual abuse to disclosure: Adults' recalls of the process towards final disclosure. Child Abuse Negl 2019:89:225-36.

13 London K, Bruck M, Ceci SJ, et al. Disclosure of child sexual abuse: what does the research tell us about the ways that children tell? Psychology, Public Policy, and Law 2005;11:194-226.

14 McElvaney R. Disclosure of child sexual abuse: delays, Nondisclosure and partial disclosure. what the research tells US and implications for practice. Child Abuse Rev 2013;24.

15 van Ham K, Brilleslijper-Kater S, van der Lee H, et al. Validation of the sexual knowledge picture instrument as a diagnostic instrument for child sexual abuse: study protocol. BMJ Paediatr Open 2020;4:e000799.

16 Castor EDC. Castor Electronic Data Capture. [Internet], 2020. Available: https://castoredc.com

17 Brilleslijper-Kater SN, Baartman HEM. What do young children know about sex? research on the sexual knowledge of children between the ages of 2 and 6 years. Child Abuse Rev. 2000;9:166-82. 